\title{
Insider Trading in the Swiss Stock Market
}

\author{
Andreas Zingg, Sebastian Lang and Daniela Wyttenbach*
}

JEL-Classification: G140

Keywords: Insider trading; Market efficiency; Swiss stock market

\section{Introduction}

The investigation of management transactions in Switzerland is of special interest because the regulation of insider trading in Switzerland is very different from other countries. Under the current law the scope of offences of illegal insider trading is surprisingly narrow. According to Article 161 of the Swiss Criminal Code (SCC), management transactions in Switzerland are only forbidden when based on "confidential information" that has a serious impact on prices. The law restricts the term "confidential information" to "the issuance of new securities, mergers or other events of similar impact". The Swiss Federal Supreme Court adheres to a restrictive interpretation of what "confidential information" is. As a result, trades based on earnings announcements, even if they contain important information such as extraordinary profits or losses, do not fall under the criminal offence of insider trading in Switzerland. The regulation on insider trading in other countries is stricter than the Swiss regulation. In the US, for example, insiders must either abstain from trading on undisclosed information or have to make this information public before they trade. The UK regulation is even stricter than the US regulation. Corporate insiders are prohibited from dealing in the securities of their own companies for a period of two months prior to the final and interim earnings announcements. Throughout the paper, we use the term insider trading to refer to the Swiss definition of (legal) insider trading or management transactions.

* University of St. Gallen, Swiss Institute of Banking and Finance, Rosenbergstrasse 52, 9000 St. Gallen. Phone: +41-71-224-70-90. E-mail: andreas.zingg@unisg.ch, sebastian.lang@unisg. ch, daniela.wyttenbach@student.unisg.ch. We would like to thank Prof. Dr. Klaus Spremann, Dr. Rico von Wyss, and Stephan Süss for their helpful comments. Furthermore we would like to thank two anonymous referees for their helpful comments.

1 Paragraph 3 of Article 161 of the Swiss Criminal Code (SCC). 
Whereas in most countries the disclosure of insider transactions has been a standard since several years, the disclosure of management transactions in Switzerland was only recently enforced on July 1 st $2005^{2}$. Therefore, little research has been done on insider trading in Switzerland so far. Ammann and Kessler (2004) investigate the behavior of stock prices and volumes on the Swiss stock exchange before and after information releases. Their study does not uncover systematic trading of insiders before the publication of information. Now, the new regulation on the disclosure of management transactions offers a new opportunity to investigate insider trading in Switzerland, using actual data on management transactions.

It can normally be assumed that corporate insiders, such as managers and board members, are better informed about the prospects of their own companies than the market. Because the exploitation of news announcements is not a criminal offence in Switzerland, insiders of publicly traded companies potentially earn high abnormal returns. Therefore, this paper examines for the Swiss stock market whether insiders can earn abnormal returns by analyzing the immediate market reaction to management transactions. Because management transactions, especially sale transactions, are often motivated by diversification and liquidity considerations and not by private information, purchase and sale transactions are investigated separately. In addition, we examine the effect of firm size and trade volume on abnormal returns of insiders. Furthermore, we analyze abnormal returns associated with clustered management transactions in order to investigate whether insiders trade greater volumes to exploit more valuable information (SEYHun, 1986). Taking into account the special regulation of insider trading in Switzerland, we investigate abnormal returns of management transactions in the run-up to quarterly earnings announcements. Finally, the investigation whether outsiders earn abnormal returns by mimicking the published management transactions helps to gain insights in assessing the degree of market efficiency of the Swiss stock market. The Efficient Market Hypothesis stated by FAMA (1970) can be accepted in its strong form only if there are no significant abnormal returns based on public and private information. In other words, insider transactions and strategies that mimic insider positions based on public information do not yield significant abnormal returns. Moreover, the semi-strong form of the Efficient Market Hypothesis states that all public information on the company's economic situation is fully and promptly incorporated in stock prices. As a result, only cor-

2 Article 74a of the Listing Rules of the Swiss Stock Exchange SWX and the Directive on the Disclosure of Managment Transactions. 
porate insiders might earn significant abnormal returns while mimicking strategies would not yield abnormal returns.

The paper is structured as follows: In Section 2, we review the previous research on insider trading. Section 3 gives a brief overview on the disclosure of management transactions in Switzerland. Section 4 provides a description and initial characterization of our data sample. In Section 5 we present the design of the event study and Section 6 presents the empirical results. Finally, Section 7 concludes.

\section{Literature Review}

In most countries corporate insiders are obliged to disclose transactions in securities of their own company. This publicly accessible data on insider trading has inspired a large academic literature that studies abnormal returns of insiders and outsiders mimicking transactions of managers. Many studies find that corporate insiders buy shares after a decline in their company's share price, and sell shares after a run-up in the share price. Subsequent to the management transaction, the trend is reversed. Thus, insiders seem to be able to time the market. JafFe (1974) and Finnerty (1976) were among the first to find this typical pattern in stock returns before and after transactions of corporate insiders. They find significant abnormal returns of insiders associated both with purchase and sale transactions. The more recent studies of RozefF and Zaman (1988), Gregory, Matako, Tonks, and Purkis (1994) and Hillier and Marshall (2002) support these findings. However, Friederich, Gregory, Matako, and Tonks (2002) as well as Fidrmuc, Goergen, and Renneboog (2006) find that insiders profit more from their purchases than from their sales. This is caused by the fact that sale transactions are often motivated by diversification and liquidity considerations, whereas purchases reflect favorable information. As a result, it is validated only for purchase transactions that insiders are able to earn abnormal returns. In contrast, for insider sales several studies find no significant abnormal returns (e.g., King and Roell, 1988; Lakonishok and Lee, 2001; Jeng, Metrick and Zeckhauser, 2003). Because of better data transparency previous research is focused on the US and the UK. However, empirical work on insider trading in other stock markets reports fairly comparable findings. For example Cheuk, FAn, and So (2006) find abnormal returns associated with legal insider transactions in Hong Kong and WISNIEwsKi and BoHL (2005) report abnormal returns of insider trading on the Warsaw Stock Exchange. 
There is strong evidence in the literature that insiders in small firms earn substantially higher abnormal returns than insiders in large firms. SEYHUN (1986) was among the first to investigate the relation between firm size and abnormal returns of insiders. He finds a negative relation between abnormal returns of insiders and firm size. The studies of Wong, Cheung and Wu (2000) and LakonishoK and Lee (2001) confirm these findings. Gregory, Matako, Tonks, and PURKis (1994) argue that abnormal returns are concentrated in small firms by the fact that managers of smaller companies are more closely in touch with the prospects of the company. Furthermore, Hillier and Marshall (2002) argue that small firms receive less analysts' coverage than large firms and therefore it is more likely for insiders to hold an informational advantage over other market participants.

Whether there is a relation between trade volume and abnormal returns of insiders is less clear in the academic literature. On the one hand, there are logical reasons to believe that the trades with the highest volume would reflect the strongest insider beliefs. Thus, following the argumentation of SEYHUN 1(986), the larger the transaction the more likely it is to be stimulated by inside information. Jeng, Metrick, and Zeckhauser (2003) as well as Fidrmuc, Goergen, and Renneboog (2006) also find abnormal returns to be higher for high-volume insider transactions. On the other hand, the requirement to disclose management transactions and the suspectedness of very large transactions might lead insiders to disguise their activity. According to the "stealth trading" hypothesis of BARCLAY and WARNER (1993) insiders make their trading less conspicuous by using one or several medium-sized trades. Friederich, Gregory, Matako, and Tonks (2002) find evidence of the "stealth trading" hypothesis and report that medium-sized trades are more informative than large ones. To complete the mixed picture concerning the relation between trade volume and abnormal returns of insiders, Givoley and Palmon (1986) find no relation between trade volume and abnormal returns of insiders.

The empirical evidence of the information content of clustered management transactions, i.e., when the same or different insiders trade closely together or even on the same day, is more clear. By purchasing shares in their firm, insiders communicate a positive signal about the prospects of their own company. Conversely, insiders signal negative news when selling shares. Thus, multiple trades are, according to Fidrmuc, Goergen, and Renneboog (2006), perceived as stronger signal by uninformed investors. Friederich, Gregory, Matako, and Tonks (2002) and Hillier and Marshall (2002) find evidence for this hypothesis investigating insider transactions on the London Stock Exchange. They both find larger abnormal returns of clustered management transactions. 
The association of insider trading and news announcements is of special interest in Switzerland, because management transactions in the run-up of price-sensitive corporate news do not fall in the category of illegal insider trading. Given the stricter US regulation on insider trading, it is not surprising that GIVOLEY and PALMON (1986) find no tendency for US insiders' purchase transactions to precede good news, respectively of sale transactions to precede bad news. Surprisingly, Ammann and Kessler (2004) corroborate these findings for the Swiss stock market, even though the regulation is less prohibitive than in the US. They find no evidence for insiders exploiting news announcements. However, it must be pointed out that their analysis is not based on real management transactions. They assume insider trading if abnormal returns and above-average trading volumes can be observed in a specific security.

More controversy arises around the issue of whether outsiders mimicking the transactions of corporate insiders are able to earn abnormal returns. Early studies by JafFe (1974) and FinNerTy (1976) find abnormal returns in the months after an insider transaction, which suggests that not only corporate insiders but also uninformed outsiders are able to earn abnormal returns. This semi-strong inefficiency is neither confirmed by SEYHUN (1986) nor by RozEFF and ZAMAN (1988). They find that abnormal returns of mimickers are eliminated by transaction costs. More recent studies investigate abnormal returns of mimicking strategies based on more selective trading rules. Bettis, Vickrey, and Vickrey (1997) report that abnormal returns, even after transaction costs, can be made by following insiders' large-volume trades. LAKONISHOK and LeE (2001) also find abnormal returns of outsiders following certain trading rules. However, they concede that the development of implementable investment strategies based on insider trading information is not straightforward.

JAFFE (1974) reports no important effects of regulatory changes on insider trading. This seems to indicate that previous research on insider trading for other stock markets should also be valid for Switzerland, even if the regulatory environment is different compared to other countries. 


\section{Swiss Regulation on the Disclosure of Management Transactions}

Even though the scope of offences that qualify as illegal insider trading is rather narrow in Switzerland, the regulation on the disclosure of management transactions is quite extensive compared to other countries. However, it must be pointed out that the current regulation governing the disclosure of management transactions was enforced only as of July 1 st $2005^{3}$. Since then, companies listed on the SWX have to disclose transactions conducted by members of the board of directors and the senior management ${ }^{4}$. Thus, in Switzerland mandatory reporting of insider transactions is limited to the top management only, which is similar to the regulation in the UK. In contrast, the US regulation on the disclosure of management transactions applies to a much larger group of insiders, including for example large shareholders and a much wider group of managers (e.g., head of functions such as sales, administration or finance on business unit level).

Persons subject to the reporting requirement are obliged to report their transactions to their company within two trading days. The substance of the reporting requirements consists of transactions in equity securities as well as conversion and share acquisition rights of their own company. Bonds, in contrast, are not subject to the reporting requirement.

If the total amount of all purchase or sale transactions concluded by a person subject to the reporting requirement exceeds the threshold of CHF 100,000 in a given calender month, the listed company must make a report to the SWX within 2 trading days ${ }^{5}$. As the notification to the SWX is administered via a Web-based reporting platform, the information is published on the SWX's website on the same day it is received. As a result, management transactions exceeding the threshold amount become public within at most four trading days, which is rather fast compared to other countries. For example in the UK it takes at most six trading days, in the US even up to 40 trading days until the transactions are public.

If the threshold is not exceeded during a given calender month, the company must make a so-called omnibus notification to the SWX within four trading days at the end of the relevant month. In general, this information is not published by the SWX. However, the listed companies are free to allow publication of all transactions, regardless of whether or not they exceed the threshold.

3 Article 74a of the Listing Rules of the SWX as well as the Directive on the disclosure of management transactions.

4 Usually direct subordinate to the board of directors or the CEO.

5 It is not permissible to offset purchases and sales. 
The publicly accessible information contains the function of the liable person as an executive member of the board or member of senior management, or as a non-executive member of the board of directors. However, although reported by the listed company, the SWX does not publish the name, the address, and the exact function of the person subject to the reporting requirement. Furthermore, the announcement published by the SWX contains whether the transaction was a purchase or a sale, the International Securities Identification Number (ISIN) and the total number traded in the relevant security, the price paid or received as well as the date on which the transaction was concluded.

Given this new regulation on the disclosure of management transactions in Switzerland, we conclude that Swiss insider transactions are likely to be very informative for the following reasons: Management transactions must be made public comparatively fast and the mandatory reporting is limited to the top management who are expected to be more knowledgeable according to the information hierarchy hypothesis of SEYHUN (1986).

\section{Data Sample}

Our analysis of insider trading in the Swiss stock market is based on a publicly accessible sample from the SWX. The sample consists of a total of 3,475 management transactions for the period between July 2005 and December 2006. In a first step, we eliminate transactions of companies for which no daily stock prices are available for the estimation window and the event window. Furthermore, we exclude investment companies for whose stocks the market making is done by persons subject to the reporting requirement. After the clearing process, we arrive at 2,302 insider transactions in the sample period. Table 1 provides the summary statistics of the data used in our study.

In general, insiders seem to do more selling than buying. The ratio of insider purchases to sales is 0.43 , as shown in Panel A. In other words 7 out of 10 insider transactions in our sample are sales. It is likely that insider sale transactions are comparatively frequent, because management compensation plans including employee stocks and stock options are widely spread in Switzerland. In particular, sale transactions are frequent in options, because exercise and sale transactions are included in the sample. These transactions seem to be mostly driven by the maturity of the option and not by insiders' motives. Therefore, we exclude transactions in stock options and build a new sample consisting only of insider transactions in stocks. Throughout the paper, we use this sample consisting of 600 purchase and 1,128 sale transactions as starting point for all further sub-samples. 
Table 1: Summary Statistics of the Insider Trading Data Used for this Study Panel A shows the total sample, whereas in Panel B multiple transactions per day are cumulated i.e., only one transaction is considered on a particular day for a given company.

\begin{tabular}{lcccc}
\hline & All transactions & Purchases & Sales & Ratio (P/S) \\
\hline A. Total sample & & & & \\
\hline No. of transactions & 2,302 & 687 & 1,615 & 0.43 \\
$\quad$ with stocks & 1,728 & 600 & 1,128 & 0.53 \\
$\quad$ with options & 574 & 87 & 487 & 0.18 \\
No. of firms & 188 & 128 & 159 & - \\
\hline B. Sample with multiple transactions per day cumulated & & \\
\hline No. of transactions & 1,791 & 507 & 1,284 & 0.39 \\
$\quad$ with stocks & 1,424 & 463 & 961 & 0.48 \\
$\quad$ with options & 367 & 44 & 323 & 0.14 \\
No. of firms & 188 & 128 & 159 & - \\
\hline
\end{tabular}

The transactions in our sample are conducted by 188 companies, hence considerably less than the total number of companies listed on the Swiss Stock Exchange. This can mainly be attributed to the fact that insider transactions below the threshold must not be published by the SWX. Therefore our sample does not include companies whose managers conducted only transactions below the threshold unless those companies have decided to report transactions voluntarily. Furthermore, some companies listed at the SWX do not allow employees to conduct insider transactions (e.g., some cantonal banks). Finally, we exclude companies because of missing stock prices. Comparing the average market capitalization of the companies in our sample with the total Swiss stock market, we find a sample bias towards larger companies. As a result, we might underestimate abnormal returns of insiders on the Swiss stock market, because abnormal returns are concentrated in small firms according to the literature. In order to be able to better understand and assess the impact of the selection bias in our sample, we build sub-samples by firm size.

To investigate abnormal returns of insiders associated with purchase and sale transactions, we consider only one transaction on a particular day for a given company. Transactions with options are excluded. Thus, our first sub-sample consists of 463 purchase transactions and 961 sales transactions, as shown in Panel B of Table 1. 
Table 2: Summary Statistics of Insider Trading Sub-Samples

Panel A shows insider transactions by firm size. Panel B shows insider transactions by trade volume. Panel C shows the number of days with multiple management transactions for a given company as well as the number of days without clustered transactions.

\begin{tabular}{lcccc}
\hline & All transactions & Purchases & Sales & Ratio (P/S) \\
\hline A. Firm size & & & & \\
\hline Small (88) & 802 & 296 & 506 & 0.58 \\
Medium (80) & 442 & 117 & 325 & 0.36 \\
Large (20) & 180 & 50 & 130 & 0.38 \\
Total & 1,424 & 463 & 961 & 0.48 \\
\hline B. Trade volume (CHF) & & & & \\
\hline $0-100,000$ & 371 & 145 & 226 & 0.64 \\
100,001-200,000 & 386 & 125 & 261 & 0.47 \\
200,001-500,000 & 368 & 110 & 258 & 0.43 \\
500,001-2,000,000 & 261 & 71 & 190 & 0.37 \\
$>$ 2,000,000 & 156 & 48 & 108 & 0.72 \\
Total & 1,542 & 499 & 1,043 & 0.51 \\
\hline C. Clustered transactions & & & & \\
\hline Dates with clustered trades & 175 & 51 & 124 & 0.41 \\
Dates w/o clustered trades & 1,249 & 412 & 837 & 0.49 \\
Total & 1,424 & 463 & 961 & 0.48 \\
\hline
\end{tabular}

In order to examine the effect of the firm size on abnormal returns of insiders, we build sub-samples by firm size. The firms are classified in three sub-samples according to their market capitalization. For this purpose, we use the classification of the three SPI subindices SPI Large, SPI Mid and SPI Small. The SPI Large comprises the 20 largest companies. The SPI Mid includes the successive 80 companies, whereas the rest of the companies is captured by the SPI Small. As shown in Panel A of Table 2, insider purchases seem to be more common among small firms. In contrast, managers of medium and large firms are less likely to purchase.

In order to be able to analyze the effect of the trade volume on abnormal returns of insiders, we build 5 sub-samples based on the CHF value of the transactions. The threshold values for the sub-samples are shown in Panel B of Table 2. Apart from transactions above CHF 2 million, the frequency of purchase transactions 
seems to be negatively related to the trade volume. SEYHUN (1988) provides a potential explanation. He finds that insiders in the US are likely to break up purchases into smaller transactions to make their trading less conspicuous for both the authority and uninformed investors. With regard to sales transactions, insiders seem not to be as concerned about being uncovered.

Finally, to analyze abnormal returns associated with clustered management transactions, we build two additional sub-samples. In the first sub-sample, we consider only transaction dates when insiders of a given company conduct multiple transactions on the same day. The second sub-sample includes all other transactions dates. Still, we consider only one transaction on a particular day for a given company. As shown in Panel C of Table 2, we find 51 transaction dates with clustered buy transactions and 124 transactions dates with clustered sale transactions.

As mentioned above, data on Swiss management transactions above CHF 100,000 is published at most four days after the transaction date, while data below that threshold is published, if at all, on a monthly basis. As a result, for insider purchases and sales not exceeding the amount of CHF 100,000, the reporting and publication date is not transparent. Hence, to analyze whether mimickers earn significant abnormal returns, we have to build additional subsamples by filtering out management transactions below CHF 100,000.

\section{Event Study Methodology}

In order to investigate whether insiders can earn abnormal returns and whether outsiders can make abnormal returns by mimicking the information of insider trades, a measure for the abnormal return is needed. For this purpose, we apply the standard methodology originally described by Fama, Fisher, Jensen, and Roll (1969). The timing sequence of our event study is illustrated in Figure 1.

Daily returns are indexed in event time using $\tau$. Defining $\tau=0$ as the event date, $\tau=T_{1}+1$ to $\tau=T_{2}$ represents the event window, and $\tau=T_{0}+1$ to $\tau=T_{1}$ constitutes the estimation window. In our event study, the event date corresponds to the transaction date of the management transaction. We choose a 61-day event window, comprised of 30 pre-event trading days, the event day, and 30 post-event trading days. Consequently, the event window ranges from $\tau=-30$ to $\tau=30$, $T_{1}$ is -31 and $T_{2}$ is 30 . Finally, the estimation window in our analysis consists of the 250 trading days before the beginning of the event window and therefore ranges from $\tau=-280$ to $\tau=-31$. $T_{0}$ takes a value of -281 .

We measure abnormal returns of management transactions using a standard event study methodology as described in BROWN and WARNER (1985). 
Figure 1: Time Line of the Event Study

The event date is defined as $\tau=0$. The event window ranges from $\tau=-30$ to $\tau=30$, while the estimation window ranges from $\tau=-280$ to $\tau=-31$.

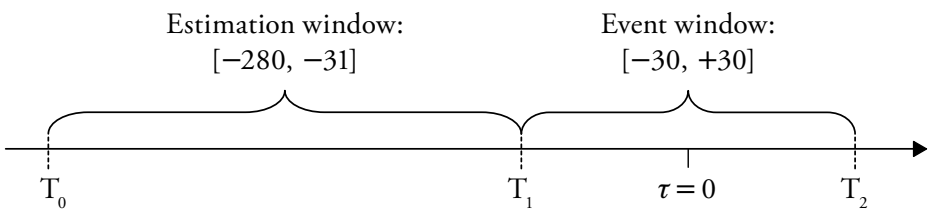

Abnormal returns are defined using an Ordinary Least Squares (OLS) market model regression:

$$
A R_{i t}=R_{i t}-\hat{\alpha}_{i}-\hat{\beta}_{i} R_{m t}
$$

where $A R_{i t}$ represents the abnormal return for firm $i$ on day $t, R_{i t}$ the return on firm $i$ 's security on day $t$ and $R_{m t}$ the return of the market index on day $t$. The parameters $\hat{\alpha}_{i}$ and $\hat{\beta}_{i}$ can be estimated over the estimation period by running an OLS regression of the stock returns on a constant and the return on the market index. The chosen market index in our event study is the Swiss Performance Index. Alternatively, a number of multifactor models have been proposed to estimate abnormal returns. However, the gains from employing multifactor models for event studies are limited according to MacKInLAY (1997), which is why we apply the market model described in equation (1).

Abnormal returns are aggregated through time and across transactions. Define $\operatorname{CAR}\left(\tau_{1}, \tau_{2}\right)$ as the cumulative abnormal return from $\tau_{1}$ to $\tau_{2}$ where $T_{1}<\tau_{1} \leq \tau_{2} \leq T_{2}$. The cumulative abnormal return from $\tau_{1}$ to $\tau_{2}$ is the sum of the included abnormal returns:

$$
\operatorname{CAR}_{i}\left(\tau_{1}, \tau_{2}\right)=\sum_{t=\tau_{1}}^{\tau_{2}} A R_{i t}
$$

The average abnormal return $A A R\left(\tau_{1}, \tau_{2}\right)$ is defined as the sum over all abnormal returns $A R_{i}$ divided by the total number of transactions $N$ :

$$
A A R\left(\tau_{1}, \tau_{2}\right)=\frac{1}{N} \sum_{t=\tau_{1}}^{\tau_{2}} A R_{i}\left(\tau_{1}, \tau_{2}\right)
$$


Finally, the cumulative average abnormal return $\operatorname{CAAR}\left(\tau_{1}, \tau_{2}\right)$ is the sum of the average abnormal returns from $\tau_{1}$ to $\tau_{2}$ :

$$
\operatorname{CAAR}\left(\tau_{1}, \tau_{2}\right)=\sum_{t=\tau_{1}}^{\tau_{2}} A A R\left(\tau_{1}, \tau_{2}\right)
$$

In order to answer the questions, whether insiders can earn abnormal returns and whether outsiders can make abnormal returns by mimicking the information of insider trades, we need to assess the statistical significance of the abnormal returns. In our paper, we apply a standardized t-test according to Mikkelson and PARTCH (1988) and a nonparametric rank test according to Corrado (1989).

The standardized t-test of MikKelson and PaRTCH (1988) considers the nonstationarity of daily stock variances. There is broad evidence that the variance of stock returns increases during the days immediately around the event date (e.g., Patell and Wolfson, 1979). Assuming that the abnormal returns are multivariate normal and cross-sectionally independent, the null hypothesis that the mean abnormal return from $\tau_{1}$ to $\tau_{2}$ is zero, where $T_{1}<\tau_{1} \leq \tau_{2} \leq T_{2}$, is tested with the following statistic $J_{1}$ :

$$
J_{1}\left(\tau_{1}, \tau_{2}\right)=\frac{1}{\sqrt{N}} \sum_{i=1}^{N}\left[\frac{\sum_{t=\tau_{1}}^{\tau_{2}} A R_{i t}}{\sqrt{\operatorname{Var} \sum_{t=\tau_{1}}^{\tau_{2}} A R_{i t}}}\right]
$$

where $\mathrm{N}$ is the number of transactions.

$$
\operatorname{Var} \sum_{t=\tau_{1}}^{\tau_{2}} A R_{i t}
$$

denotes the variance of the sum of the $A R_{i t}$ series over the time period from $\tau_{1}$ to $\tau_{2}$. The variance is defined as follows:

$$
\operatorname{Var} \sum_{t=\tau_{1}}^{\tau_{2}} A R_{i t}=\hat{\sigma}_{i}^{2}\left[T+\frac{T^{2}}{A}+\frac{T^{2}\left(\bar{R}_{m T}-\bar{R}_{m}\right)^{2}}{\sum_{t=1}^{A}\left(R_{m t}-\bar{R}_{m}\right)^{2}}\right]
$$


The value $\hat{\sigma}_{i}^{2}$ is the mean square error of the market model regression for security $\mathrm{i}, T$ is the number of days in the interval and equals $\tau_{2}-\tau_{1}+1, A$ is the number of returns in the estimation period or 250 in our event study, $\bar{R}_{m T}$ is the mean market index return from $\tau_{1}$ to $\tau_{2}$ and $\bar{R}_{m}$ is the mean market index return over the estimation period. The procedure requires the assumption that the variance of the daily stock returns during the event window is proportional to the variance over the estimation window and that the standardization factor is similar across securities.

The rank test proposed by CoRRADo (1989) does not require symmetry in cross-sectional abnormal return distributions for correct specification. The null hypothesis that the mean abnormal return is zero is tested with the following statistic $J_{2}$ :

$$
J_{2}(t)=\frac{\frac{1}{N} \sum_{i=1}^{N}\left(K_{i t}-\bar{K}\right)}{S(K)}
$$

The standard deviation $S(K)$ is calculated using all abnormal returns in the estimation and in the event window:

$$
S(K)=\sqrt{\frac{1}{k} \sum_{i=1}^{k}\left(\frac{1}{N} \sum_{i=1}^{N}\left(K_{i t}-\bar{K}\right)\right)^{2}}
$$

where

$$
\bar{K}=\frac{1}{2}(k+1)
$$

$N$ is again the number of transactions, $K_{i t}$ is the rank of $k$, or in our event study 311 , abnormal returns observed in the estimation period and in the event window and $\bar{K}$ is the expected mean rank. 


\section{Empirical Results}

\subsection{Abnormal Returns of Corporate Insiders}

We start our empirical analysis by investigating abnormal returns of insiders' aggregate purchase and sale transactions. Our sample consists of 463 purchase and 961 sale transactions. We find the typical pattern described in the literature for insider purchases and sales in the Swiss stock market. As shown in Figure 2, insiders seem to buy shares after a decline in their company's share price and seem to sell shares after a run-up in the share price. Subsequent to the insider transactions, this trend is reversed. The test statistics reported in Table 3 confirm the graphical result statistically.

Figure 2: Cumulative Average Abnormal Returns (CAARs) of Insider Purchases and Sales

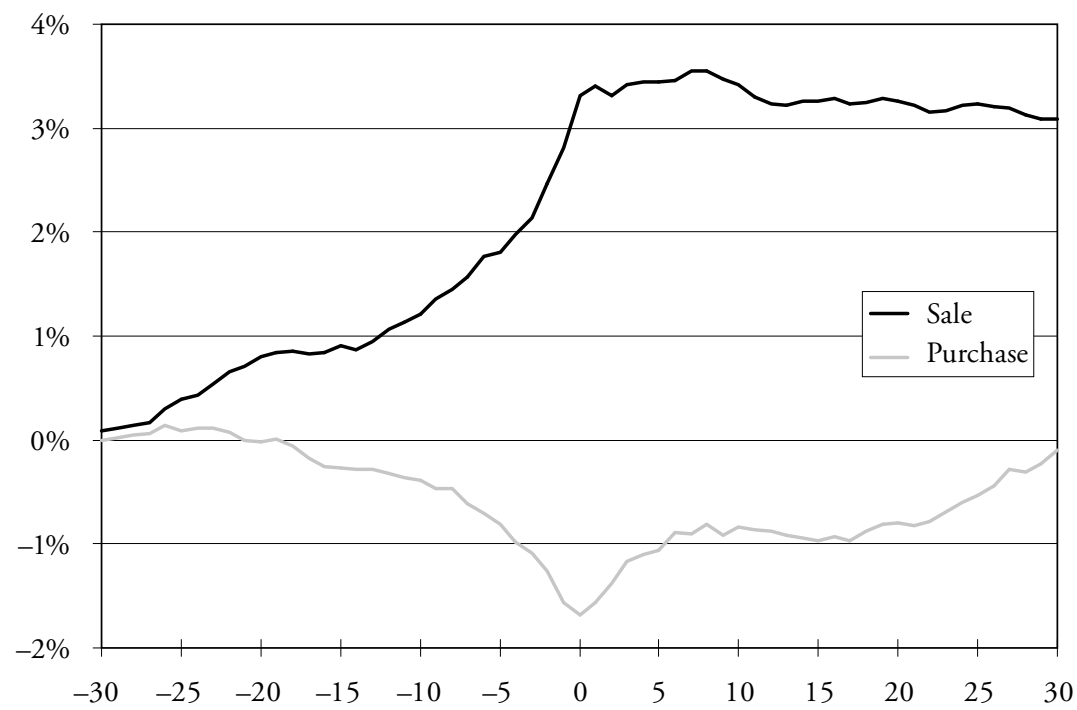

As shown in Panel A for insider purchases, cumulative average abnormal returns (CAARs) in the analyzed pre-event periods are negative and statistically significant at the $1 \%$ level. The significance is supported by both the standardized t-test and the non-parametric rank test. Thus, prices of stocks bought by corporate insiders tend to go down relative to the market in the days before the 
insider purchase transaction takes place. For corporate insiders to earn abnormal profits, CAARs in the days following the purchase transaction have to be positive and statistically significant. As shown in Panel A of Table 3, the 3-, 5-, $10-$ and 30-day CAARs are all positive and statistically significant indicating that prices of stocks bought by insiders tend to go up relative to the market after the transaction date. Hence, insiders in the Swiss stock market do earn significant abnormal returns with their purchase transactions. This is evidence against the Efficient Market Hypothesis in its strong form.

Table 3: Cumulative Average Abnormal Returns (CAARs) of Corporate Insiders' Purchases and Sales for Selected Pre- and Post-Event Periods

Test statistics for the standardized t-test of Mikkelson and Partch and for the rank correlation test of Corrado.

\begin{tabular}{|c|c|c|c|c|c|c|c|c|}
\hline & $(-30,-1)$ & $(-10,-1)$ & $(-5,-1)$ & $(-3,-1)$ & $(1,3)$ & $(1,5)$ & $(1,10)$ & $(1,30)$ \\
\hline \multicolumn{9}{|c|}{ A. Purchase transactions } \\
\hline CAAR (\%) & -1.568 & -1.206 & -0.863 & -0.580 & 0.511 & 0.624 & 0.840 & 1.586 \\
\hline T-test & $-3.275^{\mathrm{I}}$ & $-4.674^{\mathrm{I}}$ & $-5.016^{\mathrm{I}}$ & $-4.417^{\mathrm{I}}$ & $4.234^{\mathrm{I}}$ & $4.246^{\mathrm{I}}$ & $3.820^{\mathrm{I}}$ & $4.100^{\mathrm{I}}$ \\
\hline Rank test & $4.461^{\mathrm{I}}$ & $5.881^{\mathrm{I}}$ & $5.210^{\mathrm{I}}$ & $4.340^{\mathrm{I}}$ & $-4.135^{\mathrm{I}}$ & $-3.976^{\mathrm{I}}$ & $-3.857^{\mathrm{I}}$ & $-3.921^{\mathrm{I}}$ \\
\hline \multicolumn{9}{|c|}{ B. Sale transactions } \\
\hline CAAR (\%) & 2.816 & 1.686 & 1.048 & 0.844 & 0.095 & 0.129 & 0.107 & -0.230 \\
\hline T-test & $12.239^{\mathrm{I}}$ & $12.706^{\mathrm{I}}$ & $11.224^{\mathrm{I}}$ & $11.559^{\mathrm{I}}$ & 1.556 & 1.471 & 0.879 & -0.291 \\
\hline Rank test & $-9.843^{\mathrm{I}}$ & $-11.845^{\mathrm{I}}$ & $-10.635^{\mathrm{I}}$ & $-10.783^{\mathrm{I}}$ & 0.036 & -0.043 & 0.865 & 1.564 \\
\hline
\end{tabular}

${ }^{\mathrm{I}} 1 \%$ significance $\mathrm{V} 5 \%$ significance $\mathrm{x} 10 \%$ significance

For insider sale transactions (Panel B), CAARs in the pre-event period are positive and, according to both tests, statistically significant at the $1 \%$ level. Thus, insider sales in Switzerland are associated with (relative) price run-ups in the preevent period. Insiders are able to earn abnormal profits (or avoid losses) when the CAARs in the days following the sale transaction are negative and statistically significant. However, we find only a negative 30-day CAAR. Furthermore, none of the post-event CAARs is statistically significant. Therefore, we can conclude that corporate insiders in Switzerland do not earn significant abnormal returns with their sale transactions.

Summarizing, we confirm the findings of Fidrmuc, Goergen, and Renneboog (2006) and Friederich, Matako, Gregory, and Tonks (2002) for the 
Swiss stock market that insiders seem to profit more from their purchases than from their sales. The majority of insider sales seems to be motivated by liquidity and diversification aspects, so that we find no abnormal returns associated with insider sales. In contrast, insider purchases seem to be mainly informationdriven. Insiders do earn abnormal returns with their purchase transactions on the Swiss stock market.

\subsubsection{Firm Size}

Thus far, we have confined our analysis to aggregate purchase and sale transactions. In this subsection we investigate the relation between firm size and abnormal returns of insiders. Table 4 presents the results of our investigation for the Swiss stock market.

Abnormal returns by firm size associated with insider purchases are reported in Panel A of Table 4. Only for small firms we find the typical pattern that corporate insiders buy after a period of poor performance. Furthermore, the significant and positive CAARs in the post-event periods indicate, that abnormal returns are concentrated on small firms. According to our analysis, insider purchases in small firms yield on average an abnormal return of $1.928 \%$ in the 30 days following the transaction. This is considerably larger than the abnormal returns associated with insider purchases in medium-sized and large companies. Furthermore, for these companies, in the analyzed post-event periods we find significant CAARs only sporadically. In addition, the significance is only supported by the standardized t-test, whereas we find no evidence for significant abnormal returns according to the rank correlation test of CORRADo (1989).

Looking at insider sales, we find evidence for the typical price run-up in the pre-event period independent from the firm size, as shown in Panel B of Table 4. In contrast, in the post-event periods, the results are more diverse. We find significant $\mathrm{CAARs}^{6}$ only from days 1 to 10 following sale transactions of insiders in small and medium-sized firms. However, for small firms, the 10-day CAAR is positive indicating a loss for corporate insiders. The 10-day CAAR of insiders in medium-sized firms has the right sign, but transaction costs would whittle down the abnormal return to zero. The 30-day CAARs for small and mediumsized firms change signs but are statistically no longer significant. We conclude that there is no evidence for a relation between firm size and abnormal returns associated with insider sales on the Swiss stock market.

Several studies find that abnormal returns are concentrated on small firms (e.g., Seyhun, 1986; Lakonishok and Lee, 2001; Hillier and Marshall,

6 Supported by both the standardized t-test and the non-parametric rank correlation test. 
Table 4: Cumulative Average Abnormal Returns (CAARs) of Corporate Insiders' Purchases and Sales by Firm Size for Selected Pre- and Post-Event Periods

Test statistics for the standardized t-test of Mikkelson and Partch and for the rank correlation test of Corrado.

\begin{tabular}{llllllll}
\hline$(-30,-1)$ & $(-10,-1)$ & $(-5,-1)$ & $(-3,-1)$ & $(1,3)$ & $(1,5)$ & $(1,10)$ & $(1,30)$
\end{tabular}

A. Purchase transactions

Small

$\begin{array}{lcccccccc}\text { CAAR } & -2.011 & -1.619 & -0.973 & -0.469 & 0.544 & 0.685 & 1.055 & 1.928 \\ \text { T-test } & -2.810^{\mathrm{I}} & -4.480^{\mathrm{I}} & -3.766^{\mathrm{I}} & -2.075^{\mathrm{V}} & 3.048^{\mathrm{I}} & 2.933^{\mathrm{I}} & 3.285^{\mathrm{I}} & 3.404^{\mathrm{I}} \\ \text { Rank test } & 3.055^{\mathrm{I}} & 4.617^{\mathrm{I}} & 3.728^{\mathrm{I}} & 2.371^{\mathrm{V}} & -2.333^{\mathrm{V}} & -2.439^{\mathrm{V}} & -3.083^{\mathrm{I}} & -2.896^{\mathrm{I}}\end{array}$

Medium

$\begin{array}{lrrrrrrrr}\text { CAAR } & -0.706 & -0.496 & -0.763 & -0.950 & 0.507 & 0.425 & 0.426 & 1.053 \\ \text { T-test } & -0.769 & -1.199 & -2.801^{\mathrm{I}} & -4.422^{\mathrm{I}} & 2.431^{\mathrm{V}} & 1.939^{\mathrm{V}} & 1.508 & 2.042^{\mathrm{V}} \\ \text { Rank test } & 0.644 & 0.384 & 0.616 & 1.279 & -1.398 & -0.858 & 0.882 & -1.096\end{array}$

Large

\begin{tabular}{lcccccccc} 
CAAR & -0.965 & -0.425 & -0.445 & -0.373 & 0.330 & 0.727 & 0.530 & 0.810 \\
T-test & $-1.952^{\mathrm{V}}$ & -1.490 & $-1.817^{\mathrm{X}}$ & $-1.628^{\mathrm{X}}$ & $1.747^{\mathrm{X}}$ & $2.817^{\mathrm{I}}$ & 1.324 & 1.062 \\
Rank test & 0.853 & 1.029 & 0.979 & 0.738 & -0.441 & -0.743 & 0.048 & 0.021 \\
\hline \multicolumn{2}{l}{ B. Sale transactions } \\
\hline
\end{tabular}

Small

$\begin{array}{lcccccccr}\text { CAAR } & 3.097 & 1.880 & 1.189 & 0.865 & 0.256 & 0.411 & 0.553 & -0.477 \\ \text { T-test } & 10.136^{\mathrm{I}} & 9.953^{\mathrm{I}} & 9.135^{\mathrm{I}} & 8.660^{\mathrm{I}} & 2.791^{\mathrm{I}} & 3.057^{\mathrm{I}} & 3.058^{\mathrm{I}} & 0.530 \\ \text { Rank test } & -5.284^{\mathrm{I}} & -6.830^{\mathrm{I}} & -6.622^{\mathrm{I}} & -5.697^{\mathrm{I}} & -0.850 & -1.352 & -1.845^{\mathrm{X}} & 1.156\end{array}$

Medium

$\begin{array}{lcccccccc}\text { CAAR } & 3.140 & 1.561 & 0.927 & 0.815 & -0.121 & -0.247 & -0.481 & 0.116 \\ \text { T-test } & 7.171^{\mathrm{I}} & 6.552^{\mathrm{I}} & 5.528^{\mathrm{I}} & 5.975^{\mathrm{I}} & -0.873 & -1.163 & -1.712^{\mathrm{X}} & 0.153 \\ \text { Rank test } & -5.270^{\mathrm{I}} & -4.716^{\mathrm{I}} & -3.927^{\mathrm{I}} & -4.615^{\mathrm{I}} & 0.939 & 1.215 & 2.458^{\mathrm{I}} & -0.161\end{array}$

Large

\begin{tabular}{lcccccccc} 
CAAR & 0.913 & 1.244 & 0.797 & 0.831 & 0.011 & -0.030 & -0.161 & -0.136 \\
T-test & $1.940^{\mathrm{V}}$ & $4.549^{\mathrm{I}}$ & $3.753^{\mathrm{I}}$ & $4.897^{\mathrm{I}}$ & 0.106 & -0.191 & -0.936 & -0.496 \\
Rank test & -0.582 & $-1.788^{\mathrm{X}}$ & -1.331 & $-1.925^{\mathrm{X}}$ & 0.110 & 0.331 & 0.790 & 0.728 \\
\hline
\end{tabular}

I $1 \%$ significance V $5 \%$ significance $\mathrm{X}_{10 \% \text { significance }}$ 
2002). Our results on the Swiss stock market confirm these findings. We find that abnormal returns associated with insider purchases are concentrated on small firms. Insiders of medium-sized and large firms in Switzerland do not earn significant abnormal returns according to our analysis. Furthermore, we find no relation between firm size and insider sales. Insider sales seem to be motivated by liquidity and diversification aspects and less information-driven, independent from the firm size. Given these results, the selection bias in the aggregate sample towards larger companies is likely to cause an underestimation of abnormal returns associated with insider purchases. However, this selection bias does not have an impact on the interpretation of our results so far, because already the downwards biased results for insider purchases are statistically significant.

\subsubsection{Trade Volume}

In this subsection we examine the relation between trade volume and insider returns. Table 5 presents the results for insider purchases and Table 6 for insider sales.

One could argue that transactions with the highest volume reflect the strongest insider beliefs and should therefore have higher abnormal returns than low-volume trades. In contrast, the stealth trading hypothesis of BARCLAY and WARNER (1993) suggests that insiders make their trades less conspicuous by splitting large trades into several smaller trades. For insider purchases, we find some evidence for the stealth trading hypothesis. Purchase transactions below CHF 100,000 show positive and statistically significant 3-day and 5-day CAARs. The significance is supported by both statistical tests. We find positive abnormal returns also for purchase transactions between CHF 100,000 and 200,000. Insider purchases of this volume yield on average an abnormal return of $2.815 \%$ in the 30 days following the transaction date. The significance of the 30-day CAAR is again supported by both statistical tests, as shown in Table 5 . Indeed, abnormal returns associated with insider purchases above CHF 200,000 are positive and partly significant, but their significance is only supported by the standardized t-test. In contrast, the non-parametric rank test indicates no significant abnormal returns.

We find the typical pattern that insider sales are associated with (relative) price run-ups. However, the significance of abnormal returns in the analyzed pre-event periods is the weakest for sale transactions above CHF 2 million. It seems that insider sales of this volume are not concluded after a share price surge. The postevent CAARs are statistically not significant independent from the trade volume. Thus, we find no relation between trade volume and abnormal returns of insiders associated with sale transactions on the Swiss stock market. 
Table 5: Cumulative Average Abnormal Returns (CAARs) of Corporate Insiders' Purchases by CHF Trade Volume for Selected Pre- and Post-Event Periods

Test statistics for the standardized t-test of Mikkelson and Partch and for the rank correlation test of Corrado.

\begin{tabular}{|c|c|c|c|c|c|c|c|c|}
\hline & $(-30,-1)$ & $(-10,-1)$ & $(-5,-1)$ & $(-3,-1)$ & $(1,3)$ & $(1,5)$ & $(1,10)$ & $(1,30)$ \\
\hline \multicolumn{9}{|l|}{$0-100,000$} \\
\hline CAAR & -1.499 & -0.810 & -0.873 & -0.759 & 0.589 & 0.694 & 0.589 & 1.048 \\
\hline T-test & -1.475 & $-1.730^{\mathrm{X}}$ & $-2.627^{\mathrm{I}}$ & $-2.882^{\mathrm{I}}$ & $2.567^{\mathrm{I}}$ & $2.564^{\mathrm{I}}$ & $1.651^{\mathrm{X}}$ & $1.880^{\mathrm{X}}$ \\
\hline Rank test & $1.895^{\mathrm{X}}$ & $1.734^{\mathrm{X}}$ & $2.079^{\mathrm{V}}$ & $2.127^{\mathrm{V}}$ & $-2.003^{\mathrm{V}}$ & $-2.266^{\mathrm{V}}$ & 1.569 & -1.573 \\
\hline \multicolumn{9}{|c|}{$100,001-200,000$} \\
\hline CAAR & 0.471 & -1.017 & -0.718 & -0.471 & 0.276 & 0.201 & 0.868 & 2.815 \\
\hline T-test & 0.570 & $-2.240^{\mathrm{V}}$ & $-2.383^{\mathrm{V}}$ & $-1.901^{\mathrm{X}}$ & 0.971 & 0.650 & $1.978^{\mathrm{V}}$ & $4.137^{\mathrm{I}}$ \\
\hline Rank test & 0.061 & 1.392 & 0.933 & 0.524 & -0.066 & 0.144 & -1.183 & $-1.735^{\mathrm{X}}$ \\
\hline \multicolumn{9}{|c|}{$200,001-500,000$} \\
\hline CAAR & -2.343 & -1.667 & -1.145 & -0.772 & 0.805 & 0.929 & 0.891 & 0.865 \\
\hline T-test & $-3.028^{\mathrm{I}}$ & $-3.857^{\mathrm{I}}$ & $-3.894^{\mathrm{I}}$ & $-3.551^{\mathrm{I}}$ & $2.979^{\mathrm{I}}$ & $2.719^{\mathrm{I}}$ & 1.517 & 0.654 \\
\hline Rank test & 1.436 & $2.119^{\mathrm{V}}$ & $1.819^{\mathrm{X}}$ & $1.663^{\mathrm{X}}$ & -1.451 & -1.275 & -0.561 & -0.259 \\
\hline \multicolumn{9}{|c|}{$500,001-2,000,000$} \\
\hline CAAR & -2.834 & -2.114 & -0.888 & -0.288 & 0.246 & 0.870 & 0.769 & 1.670 \\
\hline T-test & $-2.202^{\mathrm{V}}$ & $-2.487^{\mathrm{V}}$ & -1.199 & -0.102 & 1.088 & $2.726^{\mathrm{I}}$ & $1.783^{\mathrm{X}}$ & 1.379 \\
\hline Rank test & 1.141 & 1.255 & 0.463 & -0.070 & -0.594 & -0.874 & -0.455 & -0.197 \\
\hline \multicolumn{9}{|l|}{$>2,000,000$} \\
\hline CAAR & -2.506 & -0.553 & -0.240 & 0.124 & 0.454 & 0.812 & 1.170 & 1.320 \\
\hline T-test & $-1.657^{\mathrm{X}}$ & -0.653 & -0.486 & 0.151 & $1.794^{\mathrm{X}}$ & $2.390^{\mathrm{V}}$ & $1.898^{\mathrm{X}}$ & 1.187 \\
\hline Rank test & 0.366 & 0.166 & 0.180 & -0.131 & -0.228 & -0.311 & -0.342 & -0.426 \\
\hline
\end{tabular}

${ }^{\mathrm{I}} 1 \%$ significance $\mathrm{V} 5 \%$ significance $\mathrm{X} 10 \%$ significance

\subsubsection{Clustered Transactions}

We speak about clustered management transactions when the same or different insiders of a specific company trade on the same day. It suggests itself to expect such clustered transactions to reflect the strongest insider beliefs. Clustered transactions would then show higher abnormal returns than unclustered trades. However, similarly to the stealth trading hypothesis, insiders will probably avoid 
Table 6: Cumulative Average Abnormal Returns (CAARs) of Corporate Insiders' Sales by Trade Volume for Selected Pre- and Post-Event Periods

Test statistics for the standardized t-test of Mikkelson and Partch and for the rank correlation test of Corrado.

\begin{tabular}{lcccccccc} 
& \multicolumn{1}{c}{$(-30,-1)$} & $(-10,-1)$ & $(-5,-1)$ & $(-3,-1)$ & $(1,3)$ & $(1,5)$ & $(1,10)$ & $(1,30)$ \\
\hline 0-100,000 & & & & & & & & \\
CAAR & 2.506 & 1.567 & 0.850 & 0.606 & -0.007 & 0.059 & 0.222 & -0.267 \\
T-test & $4.979^{\mathrm{I}}$ & $5.278^{\mathrm{I}}$ & $3.838^{\mathrm{I}}$ & $3.684^{\mathrm{I}}$ & -0.055 & 0.254 & 0.529 & 0.371 \\
Rank test & $-2.522^{\mathrm{I}}$ & $-3.239^{\mathrm{I}}$ & $-2.808^{\mathrm{I}}$ & $-2.183^{\mathrm{V}}$ & 0.749 & -0.108 & -0.473 & -0.183 \\
\hline 100,001-200,000 & & & & & & & \\
CAAR & 2.228 & 1.788 & 0.858 & 0.667 & -0.093 & 0.234 & 0.302 & -0.357 \\
T-test & $5.416^{\mathrm{I}}$ & $7.099^{\mathrm{I}}$ & $5.268^{\mathrm{I}}$ & $4.646^{\mathrm{I}}$ & -0.299 & 0.782 & 1.117 & -0.024 \\
Rank test & $-2.408^{\mathrm{V}}$ & $-4.150^{\mathrm{I}}$ & $-3.331^{\mathrm{I}}$ & $-3.391^{\mathrm{I}}$ & 0.842 & 0.069 & 0.128 & 1.216 \\
\hline 200,001-500,000 & & & & & & & \\
CAAR & 3.513 & 1.777 & 1.432 & 1.326 & 0.227 & -0.082 & -0.102 & -0.193 \\
T-test & $9.140^{\mathrm{I}}$ & $7.483^{\mathrm{I}}$ & $8.184^{\mathrm{I}}$ & $9.873^{\mathrm{I}}$ & $1.688^{\mathrm{X}}$ & 0.466 & 0.560 & 0.499 \\
Rank test & $-4.374^{\mathrm{I}}$ & $-3.869^{\mathrm{I}}$ & $-4.077^{\mathrm{I}}$ & $-5.171^{\mathrm{I}}$ & -0.548 & 0.610 & 0.041 & 0.053 \\
\hline 500,000-2,000,000 & & & & & & & \\
CAAR & 2.607 & 1.665 & 1.095 & 0.812 & 0.292 & 0.215 & -0.178 & -0.296 \\
T-test & $4.634^{\mathrm{I}}$ & $5.565^{\mathrm{I}}$ & $5.022^{\mathrm{I}}$ & $4.822^{\mathrm{I}}$ & 1.389 & 0.666 & -0.974 & -0.351 \\
Rank test & $-2.352^{\mathrm{V}}$ & $-3.391^{\mathrm{I}}$ & $-2.579^{\mathrm{I}}$ & $-2.590^{\mathrm{I}}$ & -1.101 & -0.800 & 0.724 & 0.417 \\
\hline$>2,000,000$ & & & & & & & & \\
CAAR & 3.133 & 1.561 & 1.186 & 1.113 & 0.546 & 0.946 & 1.869 & 1.705 \\
T-test & $3.505^{\mathrm{I}}$ & $3.792^{\mathrm{I}}$ & $3.851^{\mathrm{I}}$ & $4.692^{\mathrm{I}}$ & $2.587^{\mathrm{I}}$ & $2.801^{\mathrm{I}}$ & $2.901^{\mathrm{I}}$ & 1.599 \\
Rank test & -0.945 & -0.909 & -1.223 & -1.503 & -0.464 & -0.566 & -0.801 & -0.413 \\
\hline
\end{tabular}

I $1 \%$ significance V $5 \%$ significance $\mathrm{X} 10 \%$ significance

clustered transactions to make their trades less conspicuous. In this case, multiple trades were not primarily information-driven and abnormal returns associated with clustered transactions were not higher. Finally, corporate insiders can use their transactions to send a signal about the prospects of their company to uninformed investors. According to this hypothesis, clustered transactions are perceived as a stronger signal by outsiders. Larger abnormal returns of clustered management transactions would give evidence for this hypothesis. 
Table 7: Cumulative Average Abnormal Returns (CAARs) of Clustered Purchase and Sale Transactions of Corporate Insiders for Selected Pre- and Post-Event Periods

Test statistics for the standardized t-test of Mikkelson and Partch and for the rank correlation test of Corrado.

\begin{tabular}{|c|c|c|c|c|c|c|c|c|}
\hline & $(-30,-1)$ & $(-10,-1)$ & $(-5,-1)$ & $(-3,-1)$ & $(1,3)$ & $(1,5)$ & $(1,10)$ & $(1,30)$ \\
\hline \multicolumn{9}{|c|}{ A. Clustered purchase transactions } \\
\hline CAAR (\%) & 0.074 & -1.269 & -0.774 & -0.341 & 0.494 & 0.898 & 0.139 & 1.590 \\
\hline T-test & 0.085 & $-1.852^{\mathrm{X}}$ & -1.155 & -0.689 & 1.403 & $2.411^{\mathrm{V}}$ & 0.732 & $2.000^{\mathrm{V}}$ \\
\hline Rank test & 0.329 & 0.847 & 0.456 & 0.091 & -0.459 & -0.629 & -0.290 & -0.568 \\
\hline \multicolumn{9}{|c|}{ B. Clustered sale transactions } \\
\hline CAAR (\%) & 2.606 & 1.842 & 1.247 & 1.248 & 0.722 & 1.057 & 1.944 & 1.764 \\
\hline T-test & $4.417^{\mathrm{I}}$ & $5.190^{\mathrm{I}}$ & $4.843^{\mathrm{I}}$ & $6.113^{\mathrm{I}}$ & $2.843^{\mathrm{I}}$ & $2.820^{\mathrm{I}}$ & $3.911^{\mathrm{I}}$ & $2.368^{\mathrm{V}}$ \\
\hline Rank test & -1.360 & $-2.065^{\mathrm{V}}$ & $-1.750^{\mathrm{X}}$ & $-2.587^{\mathrm{I}}$ & -1.137 & -1.227 & $-1.683^{\mathrm{X}}$ & -0.682 \\
\hline
\end{tabular}

I $1 \%$ significance V $5 \%$ significance $\mathrm{X} 10 \%$ significance

As shown in Panel A of Table 7, we find no larger abnormal returns of clustered management transactions compared to aggregate insider purchases in Table 3. Furthermore, only the standardized t-test indicates significance of the 5-and the 30-day CAARs associated with clustered trades. Thus, the information content of clustered insider purchases seems not to be larger than the information content of unclustered purchase transactions on the Swiss stock market. In addition, we find no evidence for the signalling hypothesis. Consequently, our results contradict the findings of studies investigating clustered transactions in the UK and the US (Friederich, Gregory, Matatko and Tonks, 2002; Hillier and Marshall, 2002; Fidrmuc, Georgen and Renneboog, 2006). On the one hand, we can explain our results by arguing that insiders on the Swiss stock market avoid clustered transactions when their trades are information-driven. On the other hand, it must be pointed out that the sample of clustered transactions is rather small (51 trades). Therefore, the robustness of our results concerning clustered management transactions should be tested once a larger data sample is available.

As shown in Panel B of Table 7, for clustered sale transactions we find even positive abnormal returns indicating a loss for corporate insiders. Thus, clustered insider sales seem not to contain more information than unclustered transactions. 


\subsubsection{News Announcements}

Given the rather narrow scope of offences that qualify as illegal insider trading in Switzerland, insiders in the Swiss stock market may potentially exploit news announcements to earn abnormal returns. This would make a good case for closing the legal loophole in Switzerland. On the other hand, such transactions bear a high reputational risk for insiders and their companies. Furthermore, many companies listed on the Swiss stock exchange have internal governance rules that do not allow management transactions in the run-up to news announcements.

In this section we investigate abnormal returns of insider sales and purchases in the run-up to news announcements. According to Givoley and Palmon (1986) there is a prevalence of good news. They attribute this prevalence to the fact that many corporate news reports are initiated by voluntary disclosure, which are biased towards reporting favorable news. Therefore we follow Givoley and Palmon (1986) and focus on earnings announcements that are not biased in favor of good news. For this purpose we build a sub-sample consisting of management transactions that are followed by earnings announcements within 30 trading days. The publication date is based on the respective media release from the corporate website. We find a total of 83 purchase transactions and 169 sales transactions of corporate insiders in the run-up to quarterly earnings announcements.

As shown in Panel A of Table 8, we find positive CAARs in the post-event periods for insider purchases. However, only the 30-day CAAR is statistically significant according to the standardized t-test. In contrast, the non-parametric rank test does not indicate significance. Compared to aggregate insider purchases, abnormal returns of insider purchases in the run-up to news announcements are therefore not significantly higher. It seems that internal governance rules and impending reputational risks are sufficient to prevent corporate insiders from exploiting the legal loophole in Switzerland.

Similarly, we find no abnormal returns associated with insider sales in the run-up to earnings announcements, as shown in Panel B of Table 8. Only the 30 -day CAAR is significant at the $10 \%$ level according to rank correlation test. In contrast, the standardized t-test does not indicate significance.

Although the exploitation of news announcements does not fall under the criminal offence of insider trading, we find no evidence for insiders exploiting news announcements on the Swiss stock market. Thus, we confirm the findings of Ammann and Kessler (2004) for the Swiss stock market and of Seyhun (1986) and Givoley and Palmon (1986) for the UK and the US stock market. 
Table 8: Cumulative Average Abnormal Returns (CAARs) of Corporate Insiders' Purchases and Sales in the 30 Day Run-up to Quarterly Earnings Announcements for Selected Pre- and Post-Event Periods

Test statistics for the standardized t-test of Mikkelson and Partch and for the rank correlation test of Corrado.

\begin{tabular}{|c|c|c|c|c|c|c|c|c|}
\hline & $(-30,-1)$ & $(-10,-1)$ & $(-5,-1)$ & $(-3,-1)$ & $(1,3)$ & $(1,5)$ & $(1,10)$ & $(1,30)$ \\
\hline \multicolumn{9}{|c|}{ A. Purchase transactions } \\
\hline CAAR (\%) & -1.486 & -0.601 & -0.914 & -0.850 & 0.365 & 0.727 & 0.936 & 2.250 \\
\hline T-test & -0.432 & -0.931 & $-2.445^{\mathrm{V}}$ & $-2.950^{\mathrm{I}}$ & 0.503 & 1.038 & 1.263 & $2.557^{\mathrm{I}}$ \\
\hline Rank test & 0.214 & 0.545 & 1.020 & 1.202 & -0.281 & -0.604 & -0.591 & -0.807 \\
\hline \multicolumn{9}{|c|}{ B. Sale transactions } \\
\hline CAAR (\%) & 2.928 & 1.750 & 0.905 & 0.708 & 0.071 & 0.171 & 0.081 & -1.532 \\
\hline T-test & $4.980^{\mathrm{I}}$ & $4.715^{\mathrm{I}}$ & $3.493^{\mathrm{I}}$ & $3.636^{\mathrm{I}}$ & 0.255 & 0.779 & 0.741 & -1.016 \\
\hline Rank test & $-2.612^{\mathrm{I}}$ & $-3.111^{\mathrm{I}}$ & $-2.890^{\mathrm{I}}$ & $-2.939^{\mathrm{I}}$ & 0.067 & -0.317 & 0.108 & $1.654^{\mathrm{X}}$ \\
\hline
\end{tabular}

I $1 \%$ significance V $5 \%$ significance $\mathrm{X}_{10} \%$ significance

\subsection{Abnormal Returns of Mimickers}

Now we turn to the question whether outsiders can earn abnormal returns by mimicking the financial transactions of insiders in the Swiss stock market. Whereas data on insider transactions above CHF 100,000 is published at most 4 days after the transaction date, data below that threshold is published, if at all, on a monthly basis. As a result, for insider transactions below the threshold, the reporting and publication date is not transparent. Hence, to analyze abnormal returns of mimickers we exclude transactions below CHF 100,000. The remaining sample consists of 326 purchase and 765 sale transactions.

As shown in Panel A of Table 9, a substantial (relative) price surge of $0.530 \%$ is observed immediately before the outsider can process a purchase transaction. Even though the price surge continues after the mimicking transaction, abnormal returns of outsiders in the short-run are statistically not significant. Only for the 30-day CAAR the standardized t-test indicates strong significance. However, the significance is not supported by the non-parametric rank test. Furthermore, abnormal returns to outsiders were no longer significant if transaction costs were considered. Hence, we find only very limited evidence for abnormal returns of outsiders mimicking insider purchases. 
Table 9: Cumulative Average Abnormal Returns (CAARs) of Outsiders Mimicking Purchase and Sale Transactions of Corporate Insiders for Selected Pre- and Post-Event Periods

Test statistics for the standardized t-test of Mikkelson and Partch and for the rank correlation test of Corrado.

\begin{tabular}{|c|c|c|c|c|c|c|c|c|}
\hline & $(-30,-1)$ & $(-10,-1)$ & $(-5,-1)$ & $(-3,-1)$ & $(1,3)$ & $(1,5)$ & $(1,10)$ & $(1,30)$ \\
\hline \multicolumn{9}{|c|}{ A. Purchase transactions } \\
\hline CAAR (\%) & -1.132 & -0.572 & 0.071 & 0.530 & 0.096 & 0.130 & 0.211 & 1.327 \\
\hline T-test & $-1.696^{\mathrm{X}}$ & -1.510 & 0.902 & $3.680^{\mathrm{I}}$ & 0.793 & 0.695 & 0.908 & $2.831^{\mathrm{I}}$ \\
\hline Rank test & $1.821^{\mathrm{X}}$ & 1.510 & -0.507 & $-2.561^{\mathrm{I}}$ & -0.113 & -0.269 & -0.486 & -1.566 \\
\hline \multicolumn{9}{|c|}{ B. Sale transactions } \\
\hline CAAR (\%) & 3.326 & 2.019 & 1.064 & 0.139 & 0.170 & 0.080 & -0.146 & -0.379 \\
\hline T-test & $12.511^{\mathrm{I}}$ & $12.927^{\mathrm{I}}$ & $9.775^{\mathrm{I}}$ & $1.796^{\mathrm{X}}$ & 1.129 & 0.177 & -0.628 & -0.628 \\
\hline Rank test & $-9.037^{\mathrm{I}}$ & $-11.091^{\mathrm{I}}$ & $-7.751^{\mathrm{I}}$ & -0.578 & -0.398 & 0.410 & 0.700 & $1.719^{\mathrm{X}}$ \\
\hline
\end{tabular}

I $1 \%$ significance $\mathrm{V} 5 \%$ significance $\mathrm{X} 10 \%$ significance

Now we consider mimicking strategies associated with insider sales. Panel B of Table 9 reports the results of our empirical investigation. The CAARs in the post-event periods are not significant indicating that outsiders mimicking sale transactions of corporate insiders do not earn abnormal profits.

Concluding, we find no evidence for abnormal returns of outsiders mimicking insider purchases and sales. Therefore, the semi-strong Efficient Market Hypothesis cannot be rejected for the Swiss stock market.

\subsubsection{Firm Size}

In Section 6.1.1 we presented evidence for abnormal returns of insiders being concentrated on small firms. Given these results, a mimicking strategy differentiating by firm size is potentially more promising than a strategy mimicking all transactions of corporate insiders. Again, we use the classification of the three SPI subindices SPI Large, SPI Mid and SPI Small. Results are presented in Table 10.

A cross-check of the post-event windows in Panel A of Table 10 shows an expected and consistent result. We find CAARs with positive signs in the analyzed post-event windows for purchase transactions, regardless of the company size. However, only the 30-day CAAR for small firms is statistically significant, 
Table 10: Cumulative Average Abnormal Returns (CAARs) of Outsiders Mimicking Purchase and Sale Transactions of Corporate Insiders by Firm Size for Selected Pre- and Post-Event Periods

Test statistics for the standardized t-test of Mikkelson and Partch and for the rank correlation test of Corrado.

\begin{tabular}{lcccccccc} 
& \multicolumn{1}{c}{$(-30,-1)$} & $(-10,-1)$ & $(-5,-1)$ & $(-3,-1)$ & $(1,3)$ & $(1,5)$ & $(1,10)$ & $(1,30)$ \\
\hline A. Purchase transactions & & & & & & & \\
\hline Small & & & & & & & & \\
CAAR & -1.833 & -0.709 & 0.267 & 0.592 & 0.087 & 0.325 & 0.322 & 2.065 \\
T-test & $-1.709^{\mathrm{X}}$ & -0.792 & $1.719^{\mathrm{X}}$ & $2.716^{\mathrm{I}}$ & 0.407 & 1.160 & 1.135 & $2.800^{\mathrm{I}}$ \\
Rank test & 1.065 & 0.947 & -0.492 & 1.175 & -0.041 & -0.608 & -0.495 & -1.398 \\
Medium & & & & & & & & \\
CAAR & -0.309 & -0.606 & -0.350 & 0.509 & 0.080 & -0.201 & 0.148 & 0.933 \\
T-test & -0.284 & -1.551 & -1.248 & $2.172^{\mathrm{V}}$ & 0.427 & -0.425 & 0.464 & $1.855^{\mathrm{X}}$ \\
Rank test & 0.235 & 0.221 & 0.064 & -1.068 & -0.009 & 0.186 & -0.416 & -0.620 \\
Large & & & & & & & & \\
CAAR & -0.439 & 0.023 & 0.218 & 0.275 & 0.186 & 0.153 & -0.035 & 0.050 \\
T-test & -0.940 & -0.190 & 0.796 & 1.150 & 0.821 & 0.359 & -0.406 & -0.099 \\
Rank test & 0.570 & 0.369 & -0.010 & -0.230 & -0.102 & 0.085 & 0.414 & 0.204 \\
\hline
\end{tabular}

B. Sale transactions

\begin{tabular}{lcccccccc}
\hline Small & & & & & & & & \\
CAAR & 4.350 & 2.854 & 1.589 & 0.386 & 0.433 & 0.372 & -0.074 & -0.948 \\
T-test & $11.000^{\mathrm{I}}$ & $11.742^{\mathrm{I}}$ & $9.231^{\mathrm{I}}$ & $3.160^{\mathrm{I}}$ & $1.981^{\mathrm{V}}$ & 1.376 & 0.061 & -1.185 \\
Rank test & $-5.033^{\mathrm{I}}$ & $-7.035^{\mathrm{I}}$ & $-4.858^{\mathrm{I}}$ & -1.199 & -1.489 & -1.326 & -0.359 & 1.635 \\
Medium & & & & & & & & \\
CAAR & 2.968 & 1.297 & 0.531 & -0.132 & -0.106 & -0.252 & -0.257 & 0.342 \\
T-test & $6.636^{\mathrm{I}}$ & $5.135^{\mathrm{I}}$ & $3.081^{\mathrm{I}}$ & -0.836 & -0.439 & -1.069 & -0.636 & 0.926 \\
Rank test & $-4.034^{\mathrm{I}}$ & $3.391^{\mathrm{I}}$ & $-2.138^{\mathrm{V}}$ & 0.771 & 0.985 & $1.679^{\mathrm{X}}$ & 0.731 & -0.960 \\
Large & & & & & & & & \\
CAAR & 1.236 & 1.296 & 0.787 & 0.058 & 0.048 & 0.009 & -0.100 & -0.407 \\
T-test & $2.393^{\mathrm{V}}$ & $4.436^{\mathrm{I}}$ & $3.973^{\mathrm{I}}$ & 0.381 & 0.117 & -0.270 & -0.697 & -0.953 \\
Rank test & -0.805 & -1.552 & -1.385 & -0.062 & 0.275 & 0.346 & 0.514 & 1.094 \\
\hline
\end{tabular}

I $1 \%$ significance V $5 \%$ significance $\mathrm{X}_{10 \% \text { significance }}$ 
as indicated by the standardized t-test. In contrast, the rank correlation test does not indicate significance for the 30-day CAAR. All further cumulative abnormal returns are not statistically significant. Hence, outsiders seem not to be able to earn abnormal returns, not even by following a strategy mimicking insider purchases in small companies.

A similar observation can be made for sale transactions, as shown in Panel B of Table 10. For mimickers to earn abnormal returns associated with insider sales, CAARs in the post-event period have to be significant and negative. However, only the 3-day CAAR is statistically significant, but has a positive sign indicating that the corporate outsider missed a further price surge. Therefore we can conclude, that a mimicking strategy based on insider sales that differentiates by firm size does not yield statistically significant abnormal returns.

\subsubsection{Trade Volume}

Another obvious outsider trading strategy would be to differentiate by trade volume. Following the stealth trading hypothesis one would expect that mimicking smaller insider transaction volumes yields significant abnormal returns to outsiders.

Table 11 shows the results of mimicking strategies based on insider purchases for different trading volumes. It seems that outsiders can benefit from following small-volume insider purchases. We find a significant 30-day CAAR, which is supported by both the standardized t-test as well as the rank test for trade volumes between CHF 100,001 and CHF 200,000. Given the fact that both tests show significance at the $1 \%$ and the $10 \%$ level respectively, we may conclude that there seems to be some evidence in contra the semi-strong form Efficient Market Hypothesis. Hence, outsiders may - to a certain extent - be able to profit from mimicking stealth trades effectuated by corporate insiders. However, the net-profitability of such a strategy strongly depends on transaction costs. Considering transaction costs of such a mimicking strategy might reduce its attractiveness. For mimicking strategies based on insider sales, we find no significant abnormal returns (c.p. appendix Table 12).

Since we find that clustered transactions and insider transactions in the run-up to earnings announcements do not contain more information, we hypothesize that a mimicking strategy based on these insider transactions is also not profitable. Our results confirm this hypothesis. The corresponding tables can be found in the appendix. 
Table 11: Cumulative Average Abnormal Returns (CAARs) of Outsiders Mimicking Purchase Transactions of Corporate Insiders by CHF Trade Volume for Selected Preand Post-Event Periods

Test statistics for the standardized t-test of Mikkelson and Partch and for the rank correlation test of Corrado.

\begin{tabular}{|c|c|c|c|c|c|c|c|c|}
\hline & $(-30,-1)$ & $(-10,-1)$ & $(-5,-1)$ & $(-3,-1)$ & $(1,3)$ & $(1,5)$ & $(1,10)$ & $(1,30)$ \\
\hline \multicolumn{9}{|c|}{$100,001-200,000$} \\
\hline CAAR & 0.440 & -0.568 & 0.111 & 0.275 & -0.149 & 0.020 & 0.602 & 2.783 \\
\hline T-test & 0.717 & -1.156 & 0.728 & 1.018 & -0.347 & 0.400 & $1.823^{\mathrm{X}}$ & $4.088^{\mathrm{I}}$ \\
\hline Rank test & 0.017 & 0.569 & -0.162 & -0.065 & 0.088 & -0.707 & -1.170 & $-1.837^{\mathrm{X}}$ \\
\hline \multicolumn{9}{|c|}{$200,001-500,000$} \\
\hline CAAR & -1.579 & -0.433 & 0.263 & 0.807 & 0.263 & 0.263 & -0.342 & 0.546 \\
\hline T-test & $-1.895^{\mathrm{X}}$ & -1.197 & 0.522 & $2.974^{\mathrm{I}}$ & 1.025 & 0.394 & -0.815 & 0.506 \\
\hline Rank test & 0.983 & 0.704 & -0.237 & -1.513 & -0.347 & 0.138 & 0.561 & -0.057 \\
\hline \multicolumn{9}{|c|}{$500,001-2,000,000$} \\
\hline CAAR & -2.915 & -1.332 & -0.778 & 0.250 & 0.305 & 0.134 & 0.537 & 1.190 \\
\hline T-test & $-2.218^{\mathrm{V}}$ & -1.240 & -1.511 & 1.080 & 0.985 & 0.563 & 0.872 & 0.952 \\
\hline Rank test & 1.070 & 0.458 & 0.181 & -0.599 & 0.094 & 0.127 & 0.239 & 0.050 \\
\hline \multicolumn{9}{|l|}{$>2,000,000$} \\
\hline CAAR & -0.954 & 0.573 & 0.179 & 0.473 & 0.250 & 0.267 & 0.362 & 0.164 \\
\hline T-test & -0.182 & 1.502 & 1.240 & $1.823^{\mathrm{X}}$ & 0.831 & 0.463 & 0.243 & -0.019 \\
\hline Rank test & 0.139 & -0.089 & 0.085 & -0.248 & -0.110 & -0.071 & -0.344 & -0.195 \\
\hline
\end{tabular}

I $1 \%$ significance V $5 \%$ significance $\times 10 \%$ significance 


\section{Conclusion}

In this paper we investigate the pattern of security returns immediately around the trades of corporate insiders and assess the returns of outsiders who mimic management transactions in the Swiss stock market.

We find the typical pattern that insiders buy shares of their own company after a stock price decline and sell shares after a price surge. These trends are reversed in the days following the transactions. However, the trend reversal is only statistically significant for insider purchases. Our results show that insiders earn abnormal profits only with their purchase transactions. In contrast, insider sales seem to be not primarily information-driven but motivated by other aspects, such as liquidity and diversification needs. Consequently, we can reject the Efficient Market Hypothesis in its strong form for the Swiss stock market.

Investigating in greater detail the significant abnormal returns of insiders associated with purchase transactions, we find that abnormal returns are concentrated in small firms, whereas insider transactions associated with medium-sized and large firms do not yield significant abnormal returns. A potential explanation for this finding might be that small firms are less liquid and have normally a lower analyst coverage.

Our results show that information-driven management purchase transactions seem to be split up by corporate insiders into small tranches to make them less conspicuous. This confirms the stealth trading hypothesis of BARCLAY and WARNER (1993). For the same reason, insiders seem to avoid clustering their transactions when their trading actions are information-driven.

Of special interest - given the lax regulation in Switzerland - is the investigation of management transactions in connection with earnings announcements. Although management transactions based on news announcements do not fall under the criminal offence of illegal insider trading, we find no evidence that insiders exploit news announcements. The reputational risk and internal governance rules seem to be sufficient to avoid such trading behavior of corporate insiders. A revision of the existing regulatory framework seems to be not necessary according to our analysis?

We also examined whether outsiders can earn abnormal returns by mimicking transactions of corporate insiders. Given our findings, the most obvious mimicking strategies differentiate by firm size and trade volume. However, even a strategy focussing on small firms does not yield abnormal returns for outsiders after transaction costs. We obtain a more diverse picture concerning trade-volume based

7 The discussion of a draft law in parliament is scheduled for autumn 2007. 
trading strategies. It seems that outsiders can earn abnormal returns by following low-volume transactions of corporate insiders. However, taking transaction costs into account, the attractiveness of such a strategy is reduced.

Concluding, in the big picture one can reject the strong-form Efficient Market Hypothesis for the Swiss stock market, which stipulates the impossibility of abnormal returns based on private or public information. However, with regard to the semi-strong form Efficient Market Hypothesis, it remains disputable whether it is true for the Swiss stock market, as we find some evidence of positive abnormal returns from following one of the tested mimicking strategies.

\section{Appendix}

Table 12: Cumulative Average Abnormal Returns (CAARs) of Outsiders Mimicking Sale Transactions of Corporate Insiders by CHF Trade Volume for Selected Pre- and Post-Event Periods

Test statistics for the standardized t-test of Mikkelson and Partch and for the rank correlation test of Corrado.

\begin{tabular}{lcccccccc} 
& $(-30,-1)$ & $(-10,-1)$ & $(-5,-1)$ & $(-3,-1)$ & $(1,3)$ & $(1,5)$ & $(1,10)$ & $(1,30)$ \\
\hline \multicolumn{1}{c}{ 100,001-200,000 } & & & & & & & \\
CAAR & 2.669 & 1.521 & 0.652 & -0.087 & 0.401 & 0.263 & -0.068 & -0.528 \\
T-test & $6.048^{\mathrm{I}}$ & $5.721^{\mathrm{I}}$ & $3.548^{\mathrm{I}}$ & -0.297 & $2.670^{\mathrm{I}}$ & 1.476 & 0.328 & -0.127 \\
Rank test & $-2.436^{\mathrm{V}}$ & $-3.359^{\mathrm{I}}$ & $-1.795^{\mathrm{X}}$ & 0.709 & -1.184 & -0.595 & -0.031 & 1.134 \\
\hline 200,001-500,000 & & & & & & & \\
CAAR & 3.865 & 2.462 & 1.454 & 0.211 & -0.230 & -0.333 & -0.139 & -0.143 \\
T-test & $9.480^{\mathrm{I}}$ & $9.532^{\mathrm{I}}$ & $8.254^{\mathrm{I}}$ & 1.523 & -1.174 & -1.335 & 0.098 & 0.401 \\
Rank test & $-4.428^{\mathrm{I}}$ & $-5.180^{\mathrm{I}}$ & $-4.198^{\mathrm{I}}$ & -0.498 & 0.670 & 0.479 & -0.588 & -0.373 \\
\hline 500,001-2,000,000 & & & & & & & \\
CAAR & 2.947 & 1.906 & 0.880 & 0.289 & -0.045 & -0.097 & -0.565 & -0.675 \\
T-test & $5.153^{\mathrm{I}}$ & $5.937^{\mathrm{I}}$ & $3.943^{\mathrm{I}}$ & 1.378 & -0.930 & -0.933 & $-1.793^{\mathrm{X}}$ & -1.110 \\
Rank test & $-2.960^{\mathrm{I}}$ & $-3.687^{\mathrm{I}}$ & $-2.784^{\mathrm{I}}$ & -1.116 & 0.789 & 0.906 & 1.086 & 0.929 \\
\hline >2,000,000 & & & & & & & & \\
CAAR & 3.875 & 2.696 & 1.723 & 0.537 & 1.091 & 1.304 & 0.743 & 0.595 \\
T-test & $4.738^{\mathrm{I}}$ & $6.483^{\mathrm{I}}$ & $5.601^{\mathrm{I}}$ & $2.541^{\mathrm{I}}$ & $2.620^{\mathrm{I}}$ & $2.480^{\mathrm{I}}$ & 0.505 & 0.004 \\
Rank test & -1.224 & $-1.895^{\mathrm{X}}$ & -1.262 & -0.433 & -1.381 & -1.149 & -0.323 & -0.017 \\
\hline
\end{tabular}

I $1 \%$ significance V $5 \%$ significance $\mathrm{X} 10 \%$ significance 
Table 13: Cumulative Average Abnormal Returns (CAARs) of Outsiders Mimicking Clustered Purchase and Sale Transactions of Corporate Insiders for Selected Pre- and Post-Event Periods

Test statistics for the standardized t-test of Mikkelson and Partch and for the rank correlation test of Corrado.

\begin{tabular}{|c|c|c|c|c|c|c|c|c|}
\hline & $(-30,-1)$ & $(-10,-1)$ & $(-5,-1)$ & $(-3,-1)$ & $(1,3)$ & $(1,5)$ & $(1,10)$ & $(1,30)$ \\
\hline \multicolumn{9}{|c|}{ A. Clustered purchase transactions } \\
\hline CAAR (\%) & -0.152 & -0.511 & -0.002 & 0.440 & 0.103 & -0.342 & 0.467 & 0.675 \\
\hline T-test & -0.415 & -0.551 & -0.122 & 1.044 & 0.635 & -0.409 & 0.732 & 0.898 \\
\hline Rank test & 0.235 & 0.183 & -0.011 & -0.163 & -0.079 & 0.074 & -0.328 & -0.164 \\
\hline \multicolumn{9}{|c|}{ B. Clustered sale transactions } \\
\hline CAAR (\%) & 4.401 & 3.562 & 2.576 & 0.954 & 0.650 & 0.934 & 0.969 & 0.684 \\
\hline T-test & $5.977^{\mathrm{I}}$ & $7.634^{\mathrm{I}}$ & $7.593^{\mathrm{I}}$ & $3.357^{\mathrm{I}}$ & $2.151^{\mathrm{V}}$ & 2.009 & 2.015 & 1.074 \\
\hline Rank test & $-1.745^{\mathrm{x}}$ & $-2.993^{\mathrm{I}}$ & $-3.172^{\mathrm{I}}$ & -1.446 & -0.796 & -0.943 & -0.948 & -0.241 \\
\hline
\end{tabular}

I $1 \%$ significance $\mathrm{V} 5 \%$ significance $\mathrm{X} 10 \%$ significance

Table 14: Cumulative Average Abnormal Returns (CAARs) of Outsiders

Mimicking Insiders' Purchases and Sales in the 30 Day Run-Up to Quarterly Earnings Announcements for Selected Pre- and Post-Event Periods

Test statistics for the standardized t-test of Mikkelson and Partch and for the rank correlation test of Corrado.

\begin{tabular}{|c|c|c|c|c|c|c|c|c|}
\hline & $(-30,-1)$ & $(-10,-1)$ & $(-5,-1)$ & $(-3,-1)$ & $(1,3)$ & $(1,5)$ & $(1,10)$ & $(1,30)$ \\
\hline \multicolumn{9}{|c|}{ A. Purchase transactions } \\
\hline CAAR (\%) & -1.353 & -0.435 & -0.192 & 0.366 & 0.109 & 0.005 & 0.328 & 2.168 \\
\hline T-test & -0.552 & -1.185 & -0.951 & 0.520 & 0.414 & 0.150 & 1.252 & $2.772^{\mathrm{I}}$ \\
\hline Rank test & 0.016 & 0.262 & 0.272 & -0.292 & -0.313 & -0.085 & -0.487 & -0.833 \\
\hline \multicolumn{9}{|c|}{ B. Sale transactions } \\
\hline CAAR (\%) & 3.850 & 2.210 & 1.287 & 0.074 & 0.379 & 0.222 & -0.184 & -1.862 \\
\hline T-test & $6.059^{\mathrm{I}}$ & $5.422^{\mathrm{I}}$ & $4.226^{\mathrm{I}}$ & 0.305 & $1.898^{\mathrm{X}}$ & 1.402 & 0.110 & -0.979 \\
\hline Rank test & $-2.987^{\mathrm{I}}$ & $-3.656^{\mathrm{I}}$ & $-2.362^{\mathrm{I}}$ & 0.078 & -1.153 & -0.633 & 0.244 & $1.770^{\mathrm{X}}$ \\
\hline
\end{tabular}

${ }^{\mathrm{I}} \mathrm{\%}$ significance $\mathrm{V}_{5} \%$ significance ${ }^{\mathrm{X}} 10 \%$ significance 


\section{References}

Ammann, M. and S. Kessler (2004), "Information Processing on the Swiss Stock Market", Financial Markets and Portfolio Management, 18(3), pp. 256-284.

Barclay, M. J. and J. B. Warner (1993), "Stealth Trading and Volatility: Which Trades Move Prices?”, Journal of Financial Economics, 34 (3), pp. 281-305.

Bettis, C., D. Vickrey and D. W. Vickrey (1997), "Mimickers of Corporate Insiders Who Make Large-Volume Trades", Financial Analysts Journal, 53(5), pp. 57-66.

Brown, S. J. and J. B. Warner (1985), "Using Daily Stock Returns: The Case of Event Studies”, Journal of Financial Economics, 14(1) pp.3-31.

M.-Y. Cheuk, D. K. Fan and R. W. So (2006), "Insider Trading in Hong Kong: Some Stylized Facts", Pacific-Basin Finance Journal, 14(1), pp.73-90.

Corrado, C. J. (1989), "A Nonparametric Test for Abnormal Security Returns", Journal of Financial Economics, 23(2), pp. 385-395.

Fama, E. F. (1970), "Efficient Capital Markets: A Review of Theory and Empirical Work", Journal of Finance, 25(2), pp. 383-417.

Fama, E. F., L. Fisher, M. C. Jensen and R. Roll (1969), "The Adjustment of Stock Prices to New Information”, International Economic Review, 10(1), pp. 1-21.

Fidrmuc, J. P., M. Goergen and L. Renneboog (2006), "Insider Trading, News Releases and Ownership Concentration", Journal of Finance, 61(6), pp. 2931-2973.

Finnerty, J. E. (1976), "Insiders and Market Efficiency", Journal of Finance, 31(4), pp. 1141-1148.

Friederich, S., A. Gregory, J. Matatko and I. Tonks (2002), "Short-run Returns Around the Trades of Corporate Insiders on the London Stock Exchange", European Financial Management, 8(1), pp.7-30.

Givoley, D. and D. Palmon (1986), "Insider Trading and the Exploitation of Inside Information: Some Empirical Evidence", Journal of Business, 58(1), pp. 69-87.

Gregory, A., J. Matatko, I. Tonks and R. Purkis (1994), "UK Directors' Trading: The Impact of Dealings in Smaller Firms", The Economic Journal, 104(422), pp. 37-53.

Hillier, D. and A. P. Marshall (2002), "The Market Evaluation of Information in Directors' Trades", Journal of Business Finance and Accounting, 29(1 and 2), pp. 77-110.

Jaffe, J. F. (1974), "Special Information and Insider Trading", Journal of Business, 47(3), pp. 410-428. 
Jeng, L. A., A. Metrick and R. Zeckhauser (2003), "Estimating the Returns to Insider Trading: A Performance-Evaluation Perspective", The Review of Economics and Statistics, 85(2), pp. 453-471.

John, K. and B. Mishra (1990), "Information Content of Insider Trading Around Corporate Announcements: The Case of Capital Expenditures", Journal of Finance, 45(3), pp. 835-854.

King, M. and A. Roell (1988), "Insider Trading", Economic Policy, 3(1), pp. 163-193.

Lakonishoк, J. and Immoo Lee (2001), "Are Insider Trades Informative", The Review of Financial Studies, 14(1), pp.79-111.

MacKinlay, A. C. (1997), "Event Studies in Economics and Finance", Journal of Economic Literature, 35(1), pp. 13-39.

Mikkelson, W. H. and M. M. Partch (1988), "Withdrawn Security Offerings", The Journal of Financial and Quantitative Analysis, 23(2), pp. 119-133.

Patell, J. and M. Wolfson (1979), "Anticipated Information Releases Reflected in Call Option Prices”, Journal of Accounting and Economics, 1(2), pp. 117-140.

Rozeff, M. S. and M. A. Zaman (1988), "Market Efficiency and Insider Trading: New Evidence", Journal of Business, 61(1), pp. 25-44.

Seyhun, H. N. (1988), "The Information Content of Aggregate Insider Trading", Journal of Business, 61(1), pp. 1-24.

Seymun, H. N. (1986), "Insiders' Profits, Costs of Trading, and Market Efficiency”, Journal of Financial Economics, 16(2), pp. 189-212.

Wisniewski, T. P. and Martin T. Bohl (2005), "The Information Content of Registered Insider Trading Under Lax Law Enforcement", International Review of Law and Economics, 25(2), pp. 169-185.

Wong, W., Y.-L. Cheung and L. Wu (2000), "Insider Trading in the Hong Kong Stock Market”, Asia-Pacific Financial Markets, 7(3), pp. 275-288. 